\title{
Crank train concept design and balancing of an internal-combustion engine for range extending of an electric vehicle
}

\author{
Lubomír Drápal $^{1}$, Jan Vopařil ${ }^{2}$, Václav Píštěk ${ }^{3}$ \\ Institute of Automotive Engineering, Brno University of Technology, Brno, Czech Republic \\ ${ }^{1}$ Corresponding author \\ E-mail: ${ }^{1}$ drapal@fme.vutbr.cz, ${ }^{2}$ voparil@iae.fme.vutbr.cz, ${ }^{3}$ pistek.v@iae.fme.vutbr.cz
}

Received 2 September 2018; accepted 13 September 2018

DOI https://doi.org/10.21595/vp.2018.20222

Check for updates

Copyright (C) 2018 Lubomir Drápal, et al. This is an open access article distributed under the Creative Commons Attribution License which permits unrestricted use, distribution, and reproduction in any medium, provided the original work is properly cited.

\begin{abstract}
This paper presents the motivation for a range extender engine development because in comparison to power train of an electric vehicle equipped only by high-voltage battery, cost and mass saves should be reached depending on required vehicle range. The engine concept is supposed to be based on the cylinder unit of the standard ŠKODA AUTO three-cylinder engine. In order to meet power requirements and demands on costs and simplicity, the in-line two-cylinder layout is chosen for range extender. Six variants of the crank train layout are designed and compared considering mainly their balancing and vibration.
\end{abstract}

Keywords: range extender, electric vehicle, crankshaft, crank train, balancing, vibration.

\section{Introduction}

The present automotive design challenge consists in reducing depletion of fossil oil resources and decreasing fleet emissions. It can be reached by advanced vehicle power trains and drive trains, reducing aerodynamic drag, rolling resistance and vehicle lighweighting options $[1,2]$. This paper is focused on advanced vehicle powertrain. Miscellaneous concepts of power train can be used for modern passenger cars. For example: internal-combustion engine (ICE), mild hybrid, hybrid, plug-in hybrid electric vehicle (PHEV), range extender, electric motor.

Unlike a serial hybrid, where an internal-combustion engine together with generator is the main source of electricity, the range extender is an auxiliary power supply for extending of driving range of an electric vehicle, where the battery is predominantly used as a power supply for a vehicle drive. In the case of the range extender, an internal-combustion engine is not mechanically coupled with wheels and its activation is caused by achievement of a specific value of the battery state of charge during its discharging by vehicle propulsion.

According to Roland Berger's prognoses, power train with the range extender also appears to have an interesting share at new-sold passenger cars about the year 2025 [2]. Although the internal-combustion engine will be dominant power train concept, the share of range extender should reach about $14 \%$ in Europe [3], see Fig. 1.

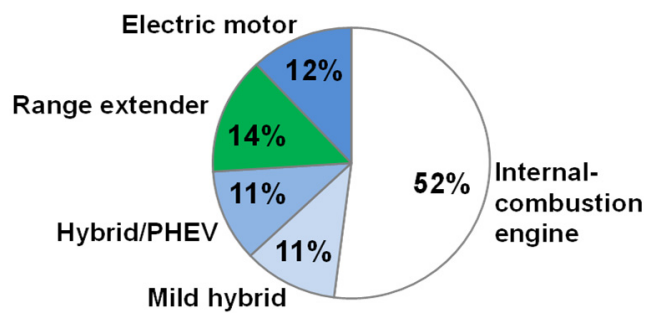

Fig. 1. Supposed share of power train concepts in the EU market at 2025 [3]

In the technical point of view, it is worth using the range extender with a small, simple and mechanically optimized internal-combustion engine [4] for an electric vehicle from specific value 
of its range depending on a vehicle class and purpose.

In comparison with further range extending by increase the energy capacity of lithium-ion battery, additional costs of the range extender are constant, and a vehicle mass increase due to volume extension of a fuel tank can be nearly neglected in this case.

Fig. 2(a) shows additional mass and Fig. 2(b) additional costs for the range extension of an electric vehicle from standard $150 \mathrm{~km}$, if lithium-ion battery is considered. Constants, used in calculation, are based on [4]. Performed analyses of potential competitors have shown that a four-stroke twin-cylinder engine concept is used in particular, although the cylinder and crankshaft arrangement are various.

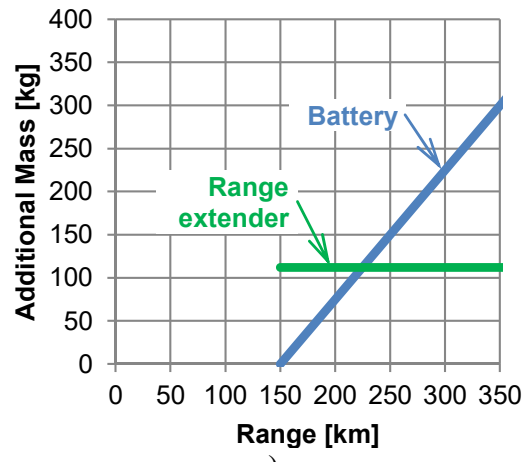

a)

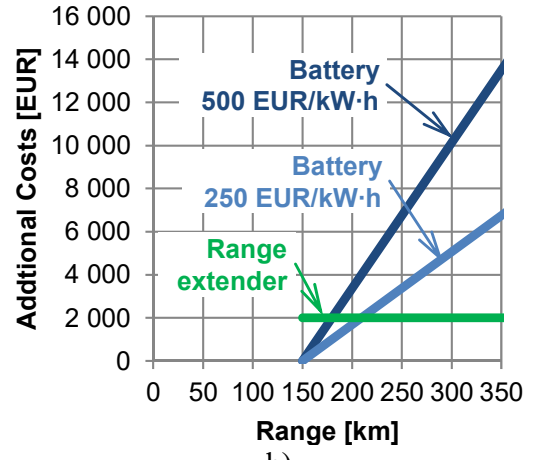

b)

Fig. 2. Additional mass and costs for a range extension of an electric vehicle from standard $150 \mathrm{~km}$

\section{An engine layout}

The range extender module has to meet strict requirements: low mass, compactness, high efficiency, excellent NVH parameters, low costs and sufficient power output. The dimensioning of the range extender is dependent on power output specifications resulting from the demands on minimum speed attainable by the electric vehicle with fully discharged high-voltage battery.

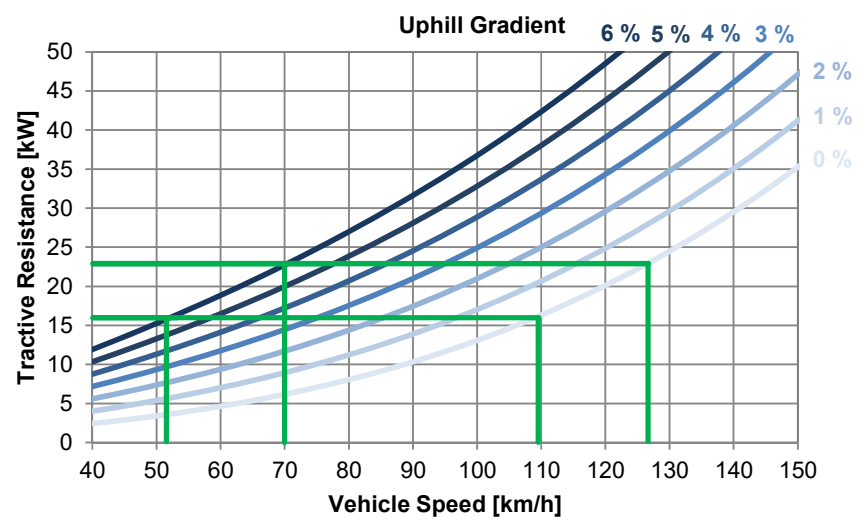

Fig. 3. Tractive resistance of considered electric vehicle (constant speed)

The minimum speed of the vehicle powered only by the range extender can work on the assumption that the vehicle's speed must be higher than speed of a heavy truck under the same driving condition.

In the Fig. 3, tractive resistance curves of considered electric vehicle for constant speed and different uphill gradient are presented. There is also marked a range of the wheels power demand.

In order to determine the desired effective power of the internal-combustion engine, an overall efficiency of the whole drive train must be taken into account: 
where $\eta_{G}$ is generator efficiency, $\eta_{C}$ is voltage converter efficiency, $\eta_{T M}$ is traction motor efficiency and $\eta_{G}$ is transmission efficiency. The rated output of the internal-combustion engine must reach accordingly from $20 \mathrm{~kW}$ to $30 \mathrm{~kW}$ for intended vehicle.

These values can be covered by miscellaneous engine concepts; however, four-stroke spark-ignition in-line two-cylinder engine derived from the standard three-cylinder engine of SKKODA AUTO is chosen. It enables reduction in research and development costs, manufacturing and service costs and simultaneously satisfies requirements mentioned above. Bore of this engine is $74.5 \mathrm{~mm}$ and stroke is $76.4 \mathrm{~mm}$ and cylinder distance is of value $82 \mathrm{~mm}$.

Crank train of an in-line two-cylinder engine can be designed with different angular offset of crank pins $\delta$, see Fig. 4. Referred offset influences: crank train balancing, smoothness of engine running, $\mathrm{NVH}$ parameters of a power unit.

For comparison purposes, three variants of crank train layout are designed: 360, 270 and 180 . The number of the variant indicates the angular offset of crank pins.

The crank train design goes out from the standard three-cylinder engine, therefore piston and connecting-rod assemblies are adopted of it.

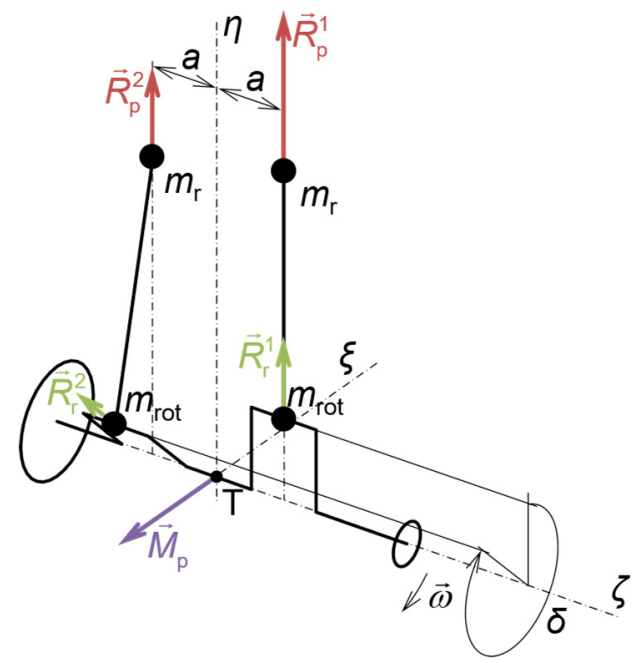

Fig. 4. Crank train scheme with vectors of unbalancing effects

\section{Crank train unbalancing effects and dynamics}

An analysis of crank train unbalancing effects is performed on the basis of definite simplifying assumptions. The effect of rotating parts is neglected because they are supposed to be fully balanced by crankshaft counterweights.

Significant parameters of crankshaft unbalancing are inertia forces of reciprocating parts $R_{p}$ (primary and secondary) and their moments $M_{p}$. In the Table 1, the crank train unbalancing effects are shown by their relative amplitudes. The angular offset of crank pins also affects time-dependent torque of the engine. Results for wide opened throttle and $4000 \mathrm{rpm}$ are shown in the Fig. 5.

The computational model has been excited by inertia effects of moving parts and gas forces are based on measurements of the original three-cylinder engine.

Modern control techniques allow even improve the time-dependent course of engine torque at variants with uneven firing order [4], however this topic will be the subject of interest of the next parts of this project [6]. 
Table 1. Crank train unbalancing effects

\begin{tabular}{|c|c|c|c|c|c|}
\hline \multirow[b]{2}{*}{$\begin{array}{c}\text { Variant } \\
\text { name }\end{array}$} & \multirow[b]{2}{*}{$\delta\left[^{\circ}\right]$} & \multicolumn{4}{|c|}{ Relative amplitude [-] } \\
\hline & & $\begin{array}{c}\text { Primary force } \\
\left(R_{p I}\right)\end{array}$ & $\begin{array}{c}\text { Secondary force } \\
\left(R_{p I I}\right)\end{array}$ & $\begin{array}{c}\text { Primary moment } \\
\left(M_{p I}\right)\end{array}$ & $\begin{array}{c}\text { Secondary moment } \\
\left(M_{p I I}\right)\end{array}$ \\
\hline 360 & 360 & 1 & 0.2634 & 0 & 0 \\
\hline 270 & 270 & 0.7071 & 0 & 0.7071 & 0.2634 \\
\hline 180 & 180 & 0 & 0.2634 & 1 & 0 \\
\hline
\end{tabular}

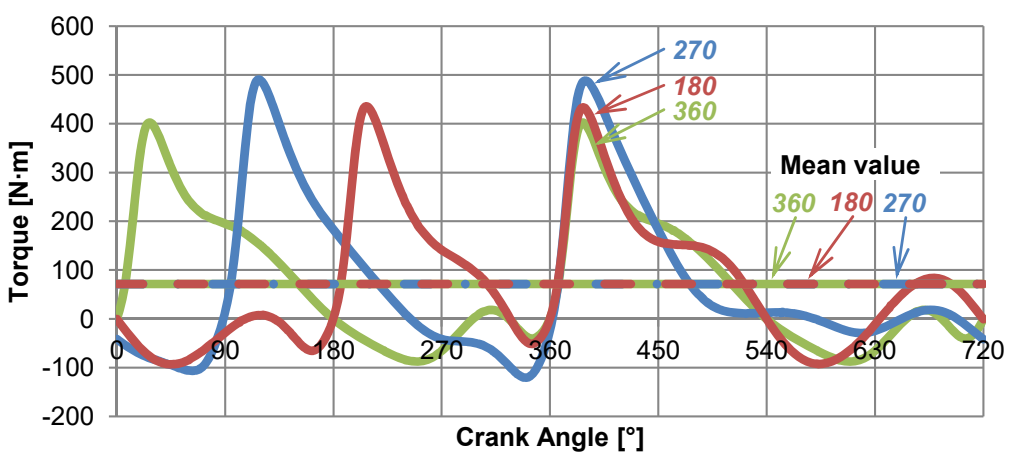

Fig. 5. Torque at crankshaft output side

\section{Crank train with a balancing unit}

The balancing unit, used for described crank train variants, consists in one contra-rotating balancing shaft and modified crankshaft counterweights which are able to eliminate primary force and moment.

This balancing unit operates on the principle of contra rotating vectors and added roll moment of the crank train, caused by the arm between exciting and balancing resultant forces, is not so critical in the point of view of the engine vibration as compared with the original primary effects.

Relative unbalancing effects of crank train equipped by the balancing unit are shown in Table 2.

Based on parameters obtained from the balancing analysis, the crank train concept design of all variants is carried out, see Fig. 6 . The new design is as compatible as possible with Škoda/VW engine family EA211 MPI to reduce costs.

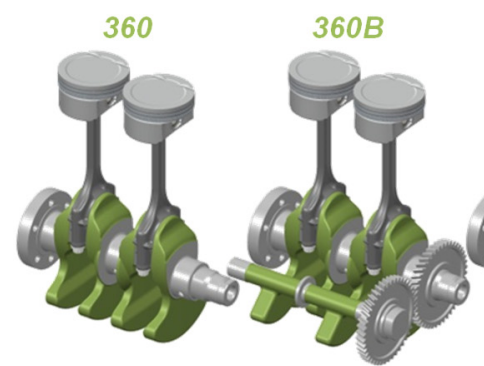

Fig. 6. The crank train concept design covering all mentioned variants

Table 2. Unbalancing effects of the crank train with the balancing unit

\begin{tabular}{|c|c|c|c|c|c|}
\hline \multirow{2}{*}{$\begin{array}{c}\text { Variant } \\
\text { name }\end{array}$} & \multirow{2}{*}{$\delta\left[^{\circ}\right]$} & $\begin{array}{c}\text { Primary force } \\
\left(R_{p I}\right)\end{array}$ & $\begin{array}{c}\text { Secondary force } \\
\left(R_{p I I}\right)\end{array}$ & $\begin{array}{c}\text { Primary moment } \\
\left(M_{p I}\right)\end{array}$ & $\begin{array}{c}\text { Secondary moment } \\
\left(M_{p I I}\right)\end{array}$ \\
\hline 360B & 360 & 0 & 0.2634 & 0 & 0 \\
\hline 270B & 270 & 0 & 0 & 0 & 0.2634 \\
\hline 180B & 180 & 0 & 0.2634 & 0 & 0 \\
\hline
\end{tabular}




\section{Conclusions}

Compared with an electric vehicle equipped only by high-voltage battery, range extender can bring interesting costs and mass reduction depending on required range of the vehicle.

However, the internal combustion-engine incorporated as the main component of the range extender module can be also the source of undesired noise and vibration. Since crank train layout significantly affects the engine $\mathrm{NVH}$, its design should be worked out attentively.

The first aspect in this stage of the project is the engine balancing and the second one is smoothness of the engine running.

In spite of the fact that 360 variant's balancing corresponds to a big single-cylinder engine, regular firing spacing offers the most engine smoothness. The balancing unit enables to eliminate primary force which amplitude is the biggest one among all variants otherwise.

The variant 180 shows primary moment instead of primary force compared with the 360 variant and this moment can be less unfavorable for vibration transmission to the car body; however, the primary moment of the 180 can be eliminated by the balancing unit as well, moreover without added roll moment. Amplitudes of the unbalancing effects of the 270 variant can be found approximately between 360 and 180 variants.

The advantage of the 270 variant with the balancing unit is inherence of only secondary moment; nevertheless the biggest torque fluctuation accompanies the engine running.

The whole powertrain running smoothness can be evaluated also by a linear torsional computational model [7], however the next stage of the project will be focused on MBS dynamics solution according to [8-10].

\section{Acknowledgement}

The research leading to these results has received funding from the MEYS under National Sustainability Programme I (Project LO1202) and Specific research Project of the Faculty of Mechanical Engineering, Brno University of Technology (FSI-S-17-4104).

\section{References}

[1] Wilhelm E., Hofer J., Schenler W., Guzzela L. Optimal implementation of lightweighting and powertrain efficiency technology in passengers' vehicles. Transport, Vol. 27, Issue 3, 2012, p. 237-249.

[2] Pieroni A., Lantieri C., Imine H., Simone A. Light vehicle model for dynamic car simulator. Transport, Vol. 31, Issue 2, 2016, p. 242-249.

[3] Automotive landscape 2025: Opportunities and challenges ahead. Roland Berger Automotive Competence Center, http://www.forum-elektromobilitaet.ch/fileadmin/DATA_Forum/Publikationen/ Roland_Berger_2011_Automotive_Landscape_2025_E_20110228.pdf

[4] Mahr B. Bassett M., Hall J., Warth M. Development of an efficient and compact range extender engine. MTZ Motorentechnische Zeitschrift, Vol. 72, 10, p. 16-23.

[5] Andert J., Köhler E., Niehues J., Schürmann G. KSPG range extender: a new pathfinder to electromobility. MTZ Motorentechnische Zeitschrift, Vol. 73, Issue 5, 2012, p. 12-18.

[6] Kučera P., Píštěk V., Prokop A., Rehák K. Measurement of the powertrain torque. Engineering Mechanics, Svratka, Czech Republic, 2018, p. 449-452.

[7] Kučera P., Píštěk V. Longitudinal and lateral dynamics of a commercial vehicle in Simulink software. Proceedings of International Conference Transport Means, Kaunas, Lithuania, 2015, p. 458-461.

[8] Zubík M., Prokop A., Řehák K. Investigation of single stage gearbox parameters including variable torque conditions. Proceedings of International Conference Transport Means, Kaunas, Lithuania, 2016, p. 720-724.

[9] Kašpárek J., Pokorný P. Analysis of the dynamics of a virtual prototype wheeled transport machine. Proceeding of International Conference Transport Means, Kaunas, Lithuania, 2014, p. 99-102.

[10] Kašpárek J., Jonák M., Škopán M. Design of the tracked chassis module. Proceeding of International Conference Transport Means, Kaunas, Lithuania, 2017, p. 666-670. 